\title{
Correction to: Lymphatic Node Metastasis Risk Scoring System: A Novel Instrument for Predicting Lymph Node Metastasis After Thymic Epithelial Tumor Resection
}

\author{
Xinxin Cheng, MD ${ }^{1}$, Yaxin Lu, $\mathrm{MD}^{2}$, Sai Chen, $\mathrm{RN}^{3}$, Weilin Yang, $\mathrm{MD}^{1}$, Bo $\mathrm{Xu}, \mathrm{MD}, \mathrm{PhD}^{1}$, \\ Jianyong Zou, $\mathrm{MD}^{4}$, and Zhenguang Chen, $\mathrm{MD}, \mathrm{PhD}^{1,4}$ \\ ${ }^{1}$ Department of Cardiothoracic Surgery of East Division, The First Affiliated Hospital of Sun Yat-Sen University, \\ Guangzhou, Guangdong, People's Republic of China; ${ }^{2}$ Department of Clinical Data Center, The Third Affiliated Hospital \\ of Sun Yat-Sen University, Guangzhou, People's Republic of China; ${ }^{3}$ Department of Center for Private Medical Service \\ and Healthcare, The First Affiliated Hospital of Sun Yat-Sen University, Guangzhou, People's Republic of China; \\ ${ }^{4}$ Department of Thoracic Surgery, The First Affiliated Hospital of Sun Yat-Sen University, Guangzhou, Guangdong, \\ People's Republic of China
}

\section{CORRECTION TO: ANN SURG ONCOL HTTPS://D OI.ORG/10.1245/S10434-021-10602-0}

The following note was missing from the original article: Xinxin Cheng, Yaxin Lu, Sai Chen, and Zhenguang Chen contributed equally to this work. The original article was corrected.
Publisher's Note Springer Nature remains neutral with regard to jurisdictional claims in published maps and institutional affiliations.

The original article can be found online at https://doi.org/10.1245/ s10434-021-10602-0.

(C) The Author(s) 2021

Published Online: 12 November 2021

Z. Chen, $\mathrm{MD}, \mathrm{PhD}$

e-mail: chzheng@mail.sysu.edu.cn 